\title{
TRANSITIVIDAD DEL VERBO SER
}

\author{
TRANSITIVITY OF THE VERB TO BE
}

Marco A. Ferrell Ramírez ${ }^{1}$

\section{RESUMEN}

Andrés Bello, el Gran Maestro de la gramática, analizando oraciones en que el pronombre lo seguido de ser reproduce el significado de verbos transitivos (como en "No se pudieron desembarcar las mercaderías, pero lo fue la gente"), comentó en el \$ $\mathbf{3 0 1}$ de su Gramática: "Este lo representativo de predicados es el caso complementario acusativo de ello". Y cuando escribe acusativo ya nos está hablando de verbo transitivo; así en la Nota VIII ("Lo" predicado) retoma el tema y dice:

“¿El verbo ser con acusativo? ¿Y por qué no? ¿Por qué cerrar los ojos a un hecho manifiesto en que no cabe disputa?

Es un principio recibido que el ser activo o neutro un verbo no depende de su significación, puesto que a un verbo neutro en una lengua corresponde muchas veces un verbo activo en otra."

Desarrollaremos esta idea.

\section{Palabras clave}

Verbo ser, transitividad, acusativo

\section{ABSTRACT}

In analysing sentences in which the Spanish neuter pronoun lo, followed by ser to be], was used to reproduce the meaning of transitive verbs (as in "No se pudieron desembarcar las mercaderías, pero lo fue la gente"), Andres Bello, Grand Master of Grammar, remarked in paragraph 301 of his Grammar: "The pronoun lo, which represents predicates, is the accusative case of ello". And as he writes accusative he undoubtedly speaks of a transitive verb; so in Note VIII ("Lo" predicado) we read:

"Is verb ser [to be] associated with the accusative case? Why not? Why should we shut our eyes to an obvious, indisputable fact?

It's a received principle that for a verb the fact of being active or neuter (stative) does not depend on its meaning, inasmuch as an active verb of a tongue may correspond to a neuter verb of another tongue."

We shall build upon this idea.

\section{Keywords}

Spanish, transitivity, verb to be

1 Excatedrático de la Universidad Nacional de Educación. Investigador en lenguas andinas, con artículos publicados. Autor del libro Manual de uso idiomático. Corrector de textos de amplia experiencia. 


\section{INTRODUCCIÓN}

El verbo ser, según las clasificaciones usuales de la gramática, es fundamentalmente intransitivo porque, de acuerdo con los criterios que informan dichas clasificaciones, no admite objeto directo. Por la clase de predicados en que aparece (predicados nominales en los que - se dice- no es núcleo) y por las relaciones que establece, se lo clasifica como verbo copulativo. Se tratará de demostrar en este artículo que el verbo ser también forma parte de predicados verbales con objeto directo.

\section{LA TESIS DE BELLO}

En su Gramática se ocupa el maestro Andrés Bello (1970 18477) del posible uso transitivo de ser al tratar sobre los demostrativos neutros. A partir de ejemplos como "Todos se precian de patriotas; y sin embargo de que muchos lo parecen icuán pocos lo son!", "No se pudieron desembarcar las mercaderías, pero lo fue la gente", "Hermoso fue aquel día, y no lo fue menos la noche", Bello afirma en el $₫ \mathbf{3 0 1}$ de su Gramática: "El lo representativo de predicados es el caso complementario acusativo de ello" (párrafo 301, cap. XV). No dice directamente que ser sea transitivo; lo da a entender. Pero en la Nota VIII expresa categóricamente: “¿El verbo ser transitivo? ¿Y por qué no? ¿Por qué cerrar los ojos a un hecho manifiesto en que no cabe disputa?" y "Es un principio recibido que el ser activo o neutro un verbo no depende de su significación, puesto que a un verbo neutro en una lengua corresponde muchas veces un verbo activo en otra". En seguida se ocupa de los matices de transitividad en los verbos estar y ser: "¿No damos a estar un acusativo reflejo cuando decimos que uno se está en el campo, se está escondido? ¿No atribuyen estas frases a la existencia una sombra de acción sobre las cualidades y modo de ser? En castellano el mismo verbo ser admite alguna vez un acusativo reflejo, lo que no haría, si no se concibiese en su significado cierto valor o apariencia de acción" (Nota VIII).

\subsection{Crítica a Bello}

Para Niceto Alcalá-Zamora, no era "manifiesto" lo de la transitividad de ser y sí cupo disputa: para él este asunto corresponde a la metafísica del lenguaje, no a la gramática. De esta manera, Alcalá-Zamora desiste de profundizar el tema en su aspecto gramatical, pese a que la argumentación de Bello no era errónea. Posiblemente la carencia de datos adicionales impidió a Bello redondear su audaz planteamiento. (Pero hasta 1945, año en que Alcalá-Zamora hizo el prólogo y las Observaciones a la obra de Bello, el idioma ya había dado, como se verá en este trabajo, ejemplos confirmatorios de lo que decía Bello.) Si se hubiera deseado emprenderla, la búsqueda de casos pertinentes habría resultado sencilla y fructífera. Hubiera bastado revisar los contextos oracionales. Viene al caso lo que el mismo Bello decía: "No los hacemos activos porque nos imaginamos una acción que no existe sino al contrario, nos figuramos una acción porque se construyen con acusativo, y porque este complemento es el que a menudo solemos juntar a los verbos que significan acción natural" (Nota VIII; las cursivas son mías). Aquí reitera (véase lo que de la Nota VIII se cita en 2 en segundo lugar) su inclinación a encontrar soluciones guiándose más por criterios sintácticos que por criterios semánticos.

\subsection{Aspecto filosófico}

En el análisis lingüístico-gramatical del verbo ser se presenta una confluencia con la Filosofía, en la cual el concepto del ser - entendiéndolo como sustantivo ("el ser") o como verboocupa un lugar fundamental. Siendo importante en nuestra exposición el recurso al concepto de transitividad, observamos que de modo semejante en Filosofía utilizan los conceptos de trascendencia y transitividad. Explica Ferrater Mora (1964: 828, t. II) que con los verbos cortar y adelgazar, y sentir y pensar se ejemplifican relaciones diferentes respecto de la transitividad:

Ahora bien los actos o acciones de la primera especie [con cortar y adelgazar] son de carácter "transeúnte"; la acción de que se habla en ellos es una actío transiens, que sale del "sujeto". Los actos o acciones de la segunda especie [con sentir $y$ pensar] son, en cambio, formas 
de la actio manens o permanens; se trata de una acción inmanente (immanens), porque permanece en el mismo "sujeto" que la ejecuta. Se dice también que la primera acción es "transitiva" y la segunda es "intransitiva".

Sobre ser nos dicen en el artículo CÓPULA que es un elemento funcional, una "partícula" (ibíd.: 358, t. I). En relación con lo que se afirma en este ensayo, debe señalarse que en el Diccionario de Filosofía dan por sentado que el verbo ser es intransitivo (ibíd.: 652, t. II):

En el presente artículo nos referiremos principalmente a lo que 'ser' designa en tanto que sustantivo o en tanto que verbo intransitivo. Ello no quiere decir que interpretemos el concepto de ser en un sentido gramatical. Pero significa que antes de cualquier análisis filosófico es necesario precisar el marco gramatical dentro del cual va a ser usado el término 'ser'.

Siendo así, desde el punto de vista filosófico el verbo ser, tal como lo definen o describen, es intransitivo. Aunque, como vemos, en Filosofía se emplean conceptos gramaticales, ello se hace con fines precisos, propios de esa rama del saber; no entran $-\mathrm{y}$, posiblemente, no tendrían que hacerlo- en análisis más detallados. Esto porque mientras en gramática, por ejemplo, las palabras es y son —que para los filósofos son "partículas" en la cópulaforman parte de un paradigma o conjunto de elementos relacionados (conjugación), en Filosofía son componentes de un enunciado que expresan la relación entre palabras (un sujeto $y$ un atributo) y el sentido del correspondiente enunciado. Además, cuando en Filosofía se estudia el ser y lo eseyente ${ }^{2}$, el significado y lo relacional importan más que la forma de la palabra; en cambio, en gramática importan la forma (Morfología), las relaciones entre palabras (Sintaxis), las relaciones $y$ consecuencias entre la forma de las palabras y sus relaciones (Morfosintaxis) y el significado, como se verá en esta exposición.

Es necesario observar que no se puede considerar que la Filosofía falla por no realizar análisis gramatical más profundo, ni que la gramática está mal porque algunos procesos de análisis o resultados no se ajustan a la lógica o a la coherencia filosófica. Bien subrayó el lingüista Charles Hockett (1979 [1958]: 16):

En realidad, se trata aquí de dos cosas distintas. Una es hasta qué punto podemos esperar que una lengua sea "lógica" en el sentido de "consistente y razonable", y hasta qué punto las lenguas difieren a este respecto. Otra es si conviene que el lingüista, en el análisis de una lengua determinada, proceda de acuerdo con alguna noción preconcebida de lógica abstracta o si es preferible que acepte lo que encuentra.

\section{CASOS MODERNOS}

Aunque el idioma español siempre ofreció en potencia la posibilidad de emplear ser como transitivo, en el tiempo de Bello no abundaban en la lengua los ejemplos pertinentes; lo que sí había y adujo nuestro gramático fueron casos que podríamos llamar "precursores" de la inequívoca presencia de ser en predicados con transitividad, aspecto en que la percepción y la conceptuación de Bello serían confirmadas por los gramáticos más de un siglo después, cuando se estableció que para hablar de transitividad más importante es la configuración sintáctica del predicado que la naturaleza transitiva o intransitiva que se atribuya al verbo. Emilio Alarcos Llorach (1972: 153) sostiene que la transitividad es una característica de ciertos predicados, pero no del verbo o núcleo del

\footnotetext{
2 'Lo que es', según el Diccionario de la Academia. La palabra derivada eseyente es lo que en gramática española se llama participio activo, que actualiza o manifiesta al actor o agente de la idea expresada en la raíz del verbo; así de ayudar sale ayudante y de florecer floreciente. Eseyente proviene del antiguo verbo eser (del lat. essěre); y como hoy la lengua tiene ser en vez de eser, correspondería usar seyente por eseyente. En los libros y diccionarios de Filosofía en alemán es normal encontrar la expresión das Seiende ('lo seyente', 'lo que es'), que viene del verbo Seien 'ser'; y así la obra De ente et essentia ('El ente y la esencia'), de Santo Tomas de Aquino, se titula en alemán Das Seiende und das Wesen ('Lo seyente y la esencia'), construcción en que con Seiende evitan que la adopción del latinismo ente de por resultado un título como Die Ente und das Wesen ('El pato y la esencia').
} 
predicado, la cual consiste en "la aparición de algún término adyacente, los llamados "objetos". Como sucede cuando alguien se adelanta a su tiempo, los planteamientos de Bello no satisficieron los requerimientos del comentador y anotador de la Gramática de Bello, Niceto Alcalá-Zamora, para quien el criterio sintáctico asumido por aquél ("los hacemos activos porque [...] se construyen con acusativo") no era suficiente para encuadrar el problema dentro de lo gramatical.

Hoy la situación es distinta, se valora $y$ comprende mejor la obra de Bello y los avances de la gramática y la Lingüística permiten apreciar mejor los fenómenos que se estudian. Como para estas cosas se necesitan datos que ayuden a sustentar lo que se dice, declaramos que ya ha sido posible aportar más ejemplos. Así, transcribiremos oraciones que representan un paso adelante de nuestro idioma en lo que toca al empleo de ser en predicados con transitividad. Suponemos que no son lo único que existe y que una mayor búsqueda permitiría encontrar más ocurrencias. Mientras, se ofrecen ejemplos que aparecen en obras del filósofo español José Ortega y Gasset (1971, 1980) y en poemas de los peruanos César Vallejo (1974) y Martín Adán (1980), los cuales confirman concluyentemente la tesis de Bello. En ellos encuentran expresión gramatical concreta las relaciones que el maestro venezolano percibió y que le sirvieron de fundamento en la mencionada Nota VIII de su Gramática. He aquí los ejemplos:

a) " $\mathrm{Si}$ no hubiese hecho estas experiencias, si no las tuviese a su espalda y las siguiese siendo en esa peculiar forma de haberlas sido, es posible que, ante las dificultades de la vida política actual, se resolviese a ensayar con ilusión, alguna de esas actitudes. Pero 'haber sido' algo es la fuerza que más automáticamente impide serlo" (Ortega y Gasset 1971: 49).

b) "Y los cincuenta años significan una realidad absoluta, no porque el cuerpo flaquea o la psiquis se afloja, cosa que a veces no acontece, sino porque a esa edad se ha acumulado más pasado viviente, se ha sido más cosas y se 'tiene más experiencia'" (Ortega y Gasset 1971: 49).

c) "Al cabo de este movimiento intelectual al través de las formas de gobierno, se encuentra con que sinceramente, con plena convicción, sólo podría aceptar una... nueva, una que no fuese ninguna de las sidas, que necesite inventarla, inventar un nuevo ser del estado" (Ortega y Gasset 1971: 51-52 (puntos suspensivos en el original)).

d) "Conocer las cosas no es serlas; ni serlas, conocerlas" (Ortega y Gasset 1980: 44).

e) "Cual mi explicación. / Esto me lacera de tempranía. / Esa manera de caminar por los trapecios. / Esos corajosos brutos como postizos. / Esa goma que pega el azogue al adentro. / Esas posaderas sentadas para arriba. / Eso no puede ser, sido. / Absurdo. / Demencia. / Pero he venido de Trujillo a Lima. / Pero gano un sueldo de cinco soles" (poema XIV de Trilce).

f) "iLlamadla! Hay que seguirla, / hasta el pie de los tanques enemigos, / que la muerte es un ser sido a la fuerza, / cuyo principio y fin llevo grabados / a la cabeza de mis ilusiones, / por mucho que ella corra el peligro corriente / que tú sabes / y que haga como que hace que me ignora. / iLlamadla! No es un ser, muerte violenta, / sino, apenas, lacónico suceso" ("Imagen Española de la Muerte", en España, Aparta de mí este Cáliz).

g) "Así, el engaño y el pavor temidos / cuando la rosa que movió la mano / golpea, adentro, al interior humano. / Que obra alguno, divino por pequeño / que no soy y que sabe, por los sidos / dioses que fui, ordenarme asá el ensueño" (soneto VI de Sonetos a la Rosa).

h) "Y tú eras algo como yo me soy, / Una gastada piedra sobre un gastado 
precipicio" (en el séptimo bloque de "La Sorpresa" en La Mano Desasida).

i) "Este ser brutal mío que es la distancia / Infinita de mi verdadero ser; / Este ser que no soy yo y me está siendo / Porque no me es nunca jamás seré" (en el bloque final de "La Sorpresa", en La Mano Desasida).

j) "iTú, Machu Picchu, divinamente humano / Cosa sida, / Sueño real y exacto / Fenecida vida vivida!" (en "La Presencia", en La Mano Desasida).

k) "Pero tú te estás parado / Entre la perpetua vez y la cosa sida" (de "Escrito para una Amiga", en La Mano Desasida).

1) "La emoción es el serte. / La emoción es el mirarte" (en La Mano Desasida).

m) "Todo lo sé, Rubén, porque ser es ser siendo... / La solapa adelante y en el puño la amiga" (del decimotercer soneto de Mi Diario).

n) "¿Tú moriste de veras una vez, Alma Sida?" (trigésimo soneto de Mi Diario).

o) "Yo voy por la pared, y nunca queda estada / De mi sombra... y tú eres mi sombra, El Alma Mía..." (del vigésimo soneto de Agosto, 1967, en Diario de Poeta).

Los ejemplos e) y f) corresponden a César Vallejo; lo reproducido de g) a o) es de Martín Adán (1980).

El empleo del verbo ser en estos quince ejemplos responde satisfactoriamente, como se explicará en seguida, a tres criterios necesarios para poder clasificarlo entre los verbos transitivos: semántico, morfológico y sintáctico.

\subsection{Criterio semántico}

Andrés Bello no dio mucha importancia al significado. Debe señalarse también que ser, mirado desde el punto de vista semántico, no ayudaba, puesto que siempre se consideró - y hasta ahora la mayoría considera- que este verbo es necesariamente intransitivo. Pero Ortega, Vallejo y Martín Adán descubren ante nuestros ojos un nuevo aspecto de este verbo: la acción o actividad. Explicitan, ponen al descubierto, la relación que ser establece entre el individuo y lo que éste es, entre el individuo y aquello que es objeto del ser del individuo y que lo sufre: si eres carpintero, se puede decir que el oficio de carpintero sufre, experimenta (para bien o para mal) tu ser carpintero. Así, si eres mal carpintero, el oficio de carpintero experimenta las consecuencias del que tú lo ejerzas. El ser no es algo que nos suceda o que nos envuelva o que se dé en nosotros en tanto entes pasivos, incapaces del ineludible quehacer vital; por eso Ortega y Gasset (1971: 9) nos dice: "La vida nos es dada, no nos la damos nosotros mismos, sino que nos encontramos en ella de pronto y sin saber cómo. Pero la vida que nos es dada no nos es dada hecha, sino que necesitamos hacérnosla nosotros, cada cual la suya. La vida es quehacer"; y César Vallejo: "Y exijo del sombrero la infausta analogía del recuerdo, / ya que, a veces, asumo con éxito mi inmensidad llorada, / ya que, a veces, me ahogo en la voz de mi vecino / y padezco" ("Y no me digan nada..." en Poemas humanos). Así, ser no implica, respecto del individuo, nada pasivo, según se ve en los ejemplos a), c), d), g), i), l) y $\mathrm{m})$, dados en 3. Ser es asumir una identidad, asumir una esencia o posibilidad existencial, instalarse, implantarse en ella y actuar desde ella, identificado con y mediante ella; ser es el ejercicio necesario de los vivientes. Pero todo aquello que podemos ser sí puede, también, tener ante nosotros un carácter pasivo (reflejo especular de lo transitivo): está siempre "expuesto" a nuestra voluntad de tratarlo como objeto de nuestro quehacer, sujeto a nuestro deseo de enriquecerlo, de asumirlo, de ejercerlo, de serlo.

Con esta significación de ser, Ortega, Vallejo y Martín Adán nos hacen entender la relación dinámica, transitiva, existente entre el individuo y aquello que él es o puede ser. En los contextos de c), e), f), j) y k), citados en $\mathbf{3}$, los participios "sidas", "sido" y "sida" tienen el mismo valor funcional que encontraríamos poniendo en 
su lugar "ensayadas" o "intentadas" (para c)), "vivido", "sufrido" o "soportado" (para e)), "creado" o "hecho" (para f)), "vivida, asumida" (para j) y k)). En f) se estaría dando ya un sentido causativo a ser: se entiende que la muerte llega a existir o ser por intervención de alguien. Si este participio no expresara una función causativa, si pensáramos que refleja una función simplemente transitiva, lo podríamos reemplazar con "experimentado" o "sufrido", con lo que se daría a entender que los murientes experimentan o sufren la muerte, o que ésta sufre o experimenta la entrada de aquéllos en su reino.

En los ejemplos a) y d), citados en $\mathbf{3}$, los pronombres objetivos (en este caso, con función de objeto directo) y la constitución de la frase revelan con claridad la presencia del verbo ser transitivo: "si no las tuviese a su espalda y no las siguiese siendo en esa peculiar forma de haberlas sido"; aquí, así como tener ("tuviese") va con su pronombre objetivo las, de igual modo ser ("siguiese siendo") trabaja con las, y si no lo queremos ver como transitivo, al menos lo parece porque con la sintaxis de toda la frase se ha mimetizado como transitivo. En la segunda oración de a), "haber sido" y "serlo" tienen - si deducimos de lo que se ve en la primera- sentido transitivo. En b) el verbo ser ("se ha sido") aparece entre dos verbos transitivos (acumular y tener), detalle estilístico que contribuye a que se capte con más facilidad el sentido y la función transitivos que el autor le infunde. La misma observación es válida para d). En g), i) y 1), la disposición y concierto de las palabras determinan que - tal como lo quiere el poeta - se sienta a ser como transitivo, idea que se confirma con la posibilidad de sustituirlo con otro verbo transitivo.

\subsection{Criterio morfológico}

Los ejemplos aducidos por Bello contienen únicamente lo (no se toma aquí en cuenta el caso que menciona del francés, con la), morfema que en su función reproductiva o referencial "disuelve" o "neutraliza" la noción de género y número presente en las palabras reproducidas o representadas. Diferente es la situación que vemos en las muestras a), d), h) $e$ i), presentadas en 3. En la primera el verbo ser aparece unido a las ("y las siguiese siendo en esa peculiar forma de haberlas sido"), morfema que sí proporciona información sobre el género y número de las palabras a que se refiere. La segunda tiene estructura semejante (infinitivo + enclítico). La tercera y la cuarta aparecen con "me", forma pronominal proclítica. Se podría poner objeciones a la tercera, sosteniendo que se trata de un uso reflexivo, a lo cual respondemos que la mayoría de gramáticos admite que a los verbos reflexivos se los puede considerar también transitivos porque hay objeto (el sujeto es objeto de su propia acción). Añadamos que todos los participios de a), c), e), f), j) y k) ilustran - como queda demostrado por la posibilidad de sustituirlos con participios de otros verbos, transitivosun uso nítidamente transitivo de ser.

\subsubsection{Casos especiales participios.}

El empleo del participio pasivo de ser en ciertos contextos no siempre indica transitividad. Este derivado verbal puede señalar simplemente la vigencia (en pasado) de la significación del verbo en relación con un individuo. Por ejemplo, los versos presentados en n) admiten la sustitución "Alma que fue". Estos otros versos de Martín Adán parecen confirmar lo anterior:

Y así voy también todo tiempo porque la uña crece

Porque aún soy la sombra de cada escena sida...

Y vivo, porque soy eterno entre la ida Cosa y la por venir como entre zeta y ese...

("Tercer soneto de Febrero", 1968, en Diario de poeta.)

No se quiere aquí generalizar y sostener que cada vez que aparece el participio pasivo (o de pasado) de ser, se puede encontrar un matiz de transitividad. Consecuentemente, no se niega que -en los versos arriba citados- "sida" es reemplazable por "que fue". Tampoco hay que olvidar que Martín Adán impone a las diversas clases de palabras (adjetivos, sustantivos, verbos, preposiciones, artículos, pronombres) nuevas funciones, distintas de las 
que normalmente les corresponden, De esto no escapa el participio pasivo de ser:

iAlma y cuerpo eres de alma

Y ya no puedes fiarte!

iHumanidad es de sido,

Y Dios es irreparable!

(En II de La campana Catalina.)

\section{También:}

iAla yo, acerve, para propia altura,

De dejación de ajeno sido y hado,

La miel, incólume, de mi amargura!

("Digitazione", en Travesía de extramares.)

Nada podría entenderse si no se observa cómo el vate pone adjetivos después de la preposición "de", en muchos otros poemas. En esta posición o secuencia, Martín Adán impone a los adjetivos una función que normalmente desempeñan los sustantivos. Pues bien, sabiendo que los participios algo tienen de adjetivos, los emplea como tales, sustantivándolos, de donde "sido" vale por "experiencia vivida" o "pasado".

Tampoco debemos pasar por alto que la palabra "sido" evoca, puesta junto a "hado", a "sino", con lo cual se da un juego conceptual: "sido" para lo retrospectivo y "hado" para lo prospectivo.

\subsubsection{Uso reflexivo de ser y estar}

Andrés Bello, según se ve en lo que se cita de la Nota VIII en 2, mostró que hay "poco trecho" entre los usos reflexivo y transitivo de un verbo, y que cuando se emplea un verbo con pronombres reflexivos estamos a un paso de usarlo como transitivo, aunque este verbo sea ser. Además de h), Martín Adán nos proporciona muchísimos ejemplos de este uso de ser:

¡Cuánto me soy si lo imagino!

(De "Mundo", en La mano desasida.)

Cargada de tu cuerpo, como soy yo el macho,

El macho que me soy a dios inteligente,

Cualquiera..., y que no soy sino un brío y un cacho.
(Del décimo soneto de Marzo, 1967, en Diario de poeta.)

\section{Sete una sola en secreto}

(De "Escrito para una Amiga", en La mano desasida.)

No es, pues, del todo insólito que un verbo reflexivo pueda usarse como transitivo, aun cuando al comienzo tal uso reflexivo se haya efectuado "inocentemente", es decir, sin intención de llegar a la transitividad. Martín Adán da uso transitivo al verbo ser y también al verbo estar ("queda estada", véase o), que aparece en $\mathbf{3}$ ).

\subsection{Criterio sintáctico}

Tomando por punto de partida la base aportada por el ensanchamiento semántico de ser, resulta menos difícil aceptar que la tesis de Bello se puede confirmar totalmente. Pero es el comportamiento sintáctico de ser lo que termina ubicándolo, quiérase o no, entre los verbos transitivos. A esto contribuyen también los componentes morfológicos analizados en $\mathbf{3 . 2 . 1}$ y $\mathbf{3 . 2 . 2}$ (es muy normal que en los fenómenos lingüísticos se interrelacionen lo morfológico, lo sintáctico y lo semántico).

De las muestras reproducidas en $\mathbf{3}$, son a), d), g), i) y k) las que desde el punto de vista sintáctico presentan con más claridad características estructurales propias de aquellas en que se emplean verbos transitivos. En a), la conformación de las primeras proposiciones subordinadas — con los verbos transitivos hacer ("hecho") y tener ("tuviese") — es tal, que arrastra al verbo ser y lo encasilla entre los transitivos, lo asimila a esta clase de verbos. En un análisis gramatical somero, diríamos — siguiendo la terminología de Emilio Alarcos Llorachque en esta oración, al producirse la elusión (omisión) del término adyacente (en este caso, el objeto directo "estas experiencias"), "persiste un indicador de su función junto al núcleo que además hace una referencia al número y género del sintagma omitido: el núcleo queda incrementado con un referente pronominal (en los ejemplos anteriores: 
las come, lo bebe, la escribe). A este tipo de términos adyacentes lo llamamos implemento y a la función que desempeña implementación" (Alarcos Llorach 1972: 153). En d) -caso que tal vez refleja alguna influencia del alemán, posibilidad que debe investigarse - el infinitivo se articula en la primera proposición con una forma pronominal y da serlas, que se compadece con serlas y conocerlas de la segunda proposición. El -las unido a los tres infinitivos tiene función de objeto directo.

En g) el participio ("sidos") se presenta en el marco de una proposición subordinada de relativo que - en armonía con la función de adjetivo que desempeña- se resuelve en forma de adjetivo: "que fui" equivale a "sidos por mí". Para entender mejor este proceso, empleemos "conocer" en lugar de "ser"; y tendríamos así que "dioses que conocí" es equivalente a "dioses conocidos por mí", construcción que en la estructura profunda tiene "conocer dioses", donde "dioses" es objeto. En i), donde no es fácil establecer límites oracionales y, por tanto, proposicionales, podemos aislar en el tercer verso una proposición subordinada de relativo ("que me está siendo"), la cual tiene un núcleo - la frase verbal "está siendo", cuyo elemento principal es el verbo ser ("siendo")- que funciona con me, objeto directo. En el cuarto verso, la proposición subordinada causal tiene un núcleo ("es") que se articula con el objeto directo me. Ciertamente, en ambos casos el verbo ser no funciona como copulativo ni se puede hablar, consecuentemente, de predicados nominales sino de predicados verbales. Comentemos de paso que los versos tercero y cuarto de i) nos dicen que el poeta está siendo sido por otro ser, el cual está asumiendo la identidad o ser de Martín Adán (muy a pesar de este caballero, en él - según sus versosestá acaeciendo una superposición de personalidades). En 1) _-"La emoción es el serte. / La emoción es el mirarte" - , como en a) y en d), la trabazón de la frase (expresada en el recurso estilístico del paralelismo) pone en pie de igualdad a los verbos ser y mirar: cada uno tiene su pronombre enclítico, que cumple la función de objeto directo.

No está de más señalar, por otra parte, que en algunos poemas de Vallejo no es fácil determinar con exactitud qué pasa con el verbo ser, qué función o equivalencia tiene: "Tal siento ahora el meñique / demás en la siniestra. Lo veo y creo / no debe serme, o por lo menos que está / en sitio donde no debe" (poema XXXVI de Trilce), y "Ya ni he de violentarme a que me seas, / de para nunca; ya no saltaremos / ningún otro postillo querido" (poema LXXII de Trilce). En ambos poemas, "me" puede tomar el valor de objeto directo o de objeto indirecto, según la intención que descubramos en el poeta.

\section{CONCLUSIONES}

Los ejemplos presentados ${ }^{3}$ permiten llegar a la conclusión de que el verbo ser no solo es empleado en los llamados predicados nominales, sino también en los predicados verbales transitivos. Las razones que fundamentan este aserto son las siguientes:

a) el contenido semántico de que está cargado el verbo ser en los ejemplos aducidos (se lo usa con un sema transitivo y en otros casos con un sema causativo). Esta cualidad semántica se manifiesta en los niveles morfológico y sintáctico.

b) el empleo de formas pronominales en función de objeto directo en casos de elusión (omisión), en oraciones cuya construcción determina la aparición obligatoria de dichas formas pronominales.

c) La sintaxis de las oraciones en que se da este uso de ser, la cual es propia de aquellas que tienen verbos transitivos.

3 En cuanto a fechas, podemos señalar que los ejemplos tomados de Ortega (a), b) y c)) fueron publicados por primera vez en 1931 y en 1925 (d)). De la obra poética de Vallejo, hay que indicar que Trilce se publicó en 1919; y España, Aparta de mí este Cáliz, en 1938. De los ejemplos de Martín Adán, solo g) apareció en fecha en que Niceto Alcalá-Zamora pudo haberlo leído, ya que estos poemas de Sonetos a la Rosa se publicaron de 1931 a 1942 


\section{REFERENCIAS}

Academia Española (1970) Diccionario de la Lengua Española, Madrid, Espasa-Calpe S. A.

Academia Española (1973) Esbozo de una Nueva Gramática de la Lengua Española, Madrid, Espasa-Calpe S. A.

Alarcos Llorach, Emilio (1972) "Verbo Transitivo, Verbo Intransitivo y Estructura del Predicado" en Estudios de Gramática Funcional del Español, Madrid, Gredos, 148-162.

Bello, Andrés (1970 [1847]) Gramática de la Lengua Castellana, Buenos Aires, Sopena Argentina. Notas de Rufino J. Cuervo y prólogo y Observaciones de Niceto Alcalá-Zamora.

Ferrater Mora, José (1964) Diccionario de Filosofía, 2 t., Buenos Aires, Editorial Sudamericana, 5. ${ }^{\text {a edición. }}$

Hockett, Charles F. (1979 [1958]) Curso de Lingüísitca moderna, Buenos Aires, Editorial Universitaria de Buenos Aires, $4 .^{\text {a }}$ edición. Traducción del inglés de Emma Grgores y Jorge Alberto Juárez.

Martín Adán (seudónimo) (1980) Obra Poética, Lima, Ediciones Edubanco (Banco Continental). Edición de Ricardo Silva-Santisteban.

Ortega y Gasset, José (1971) Historia como sistema, Madrid, Espasa-Calpe S. A.

Ortega y Gasset, José (1980) Estudios sobre el amor, Madrid, Revista de Occidente.

Seco, Manuel (1972) Manual de gramática esencial del español, Madrid, Aguilar.

Vallejo, César (1974) Obra Poética Completa, Lima, Mosca Azul Editores. Contiene Los Heraldos Negros, Trilce, Poemas en Prosa, Poemas Humanos y España, Aparta de mí este Cáliz.

Fecha de recepción: 02 de marzo 2015

Fecha de aceptación: 27 de abril 2015 